\title{
Studies on the Relationship between the Number of Arteriae Rectae of Intestinal Artery and Intestinal Length
}

\author{
Tsuneo Chiba and E. Thomas Boles, Jr. \\ The Second Department of Surgery, Tohoku University \\ School of Medicine, Sendai 980 and Columbus Children's \\ Hospital, Ohio, USA
}

Criba, T. and Boles, E.T., Jr. Studies on the Relationship between the Number of Arteriae Rectae of Intestinal Artery and Intestinal Length. Tohoku J. exp. Med., 1984, 143(1), 27-31 — In the measurement of the length of preserved intestine after massive resection of the intestine, measurement of the length of intestine as it is at the time of operation may produce a large error when compared to the length of the intestine at normal times. Therefore, attention was paid to the number of arteriae rectae of the intestinal artery and a comparison was made between such number and the length of the intestine at normal times in rats and man. As a result, the conclusion was drawn that the measurement of arteriae rectae of the intestinal artery is useful for the estimation of preserved intestine at normal times. — intestinal artery; arteriae rectae; intestinal length

In massive small bowel resection, the length of intestine to be excised and to be preserved is an important factor. The oral side of this type of intestine is extremely wide and extended while the anal side is thin and short as it has not been used. Therefore, to measure the length of the intestine as it is during surgery would result in an error when compared to the length at normal times. To solve this problem, it is necessary to estimate the normal length by using certain referential indices. As one such index, the number of arteriae reactae of the intestinal artery is used and related to the normal length of the intestine.

\section{Materials and Methods}

One hundred and seventy-seven Sprague-Dawley rats were subjected to laparotomy under pentobarbital anesthesia. The abdominal cavity was sufficiently opened to avoid artificial traction of the intestine and a 1-0 silk thread was led along the antimesenteric side of the intestinal wall and measured its length from the pylorus to the terminal ileum. The number of arteriae rectae of the intestinal artery in the same region was counted (Fig. 1). Many of the intestinal arteries run parallel to the intestinal veins. Their constructions are diverse but in principle each one reaching the intestinal wall was counted as one and the total number was calculated. Then the number of intestinal arteries in the region about 2 $\mathrm{cm}$ away from the intestinal wall was also counted for reference. Since the body length of rats is difficult to measure, the rats were divided into five groups by body weight; group 1

Received for publication, July 6, 1983. 


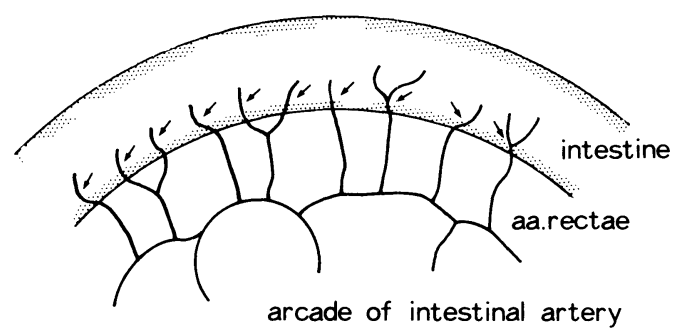

Fig. 1. Method of measurement of the arteriae rectae of the intestinal artery. When the arteriae rectae or their branches reach the intestinal wall, each is counted as one.

(40-60 g), group 2 (90-110 g), group 3 (200-300 g), group 4 (301-400 g), and group 5 (over $401 \mathrm{~g})$. In order to investigate their correlation in human, 10 adults having diseases unrelated to the small intestine were selected at random and the same calculation was made on those patients.

\section{RESULTS}

Table 1 shows the length of the small intestine, the number of arteriae rectae of the intestinal artery and the number of intestinal arteries in the region about $2 \mathrm{~cm}$ away from the intestinal wall for each group. The values in the Table represent the mean values and the range of measured values in parenthesis. They all indicate roughly normal distribution, with mean values falling at around the median point of each range. The length of the small intestine was found to increase as the body weight increases; but with the rats of over $300 \mathrm{~g}$, no difference was observed. No difference was noticed between sexes. The length of the intestine of mature rats was nearly twice that of the rats of group 1 . The number of arteriae rectae of the rats fell within a narrow range of 280-326 and its distribution was as shown in Fig. 2. The number was in the range of 290-309 for 140 cases $(80 \%)$ and the mean value of all cases was 299 . No remarkable change in the number of arteriae rectae of the intestinal artery was found throughout the life of rats. Also, no significant difference was noticed between groups as regards

TABLE 1. Length of the intestine and the number of intestinal vessels in rats

\begin{tabular}{cccccc}
\hline Group & $\begin{array}{c}\text { Body weight } \\
(\mathrm{g})\end{array}$ & $\begin{array}{c}\text { Number of } \\
\text { rat }\end{array}$ & $\begin{array}{c}\text { Length of } \\
\text { intestine }(\mathrm{cm})\end{array}$ & $\begin{array}{c}\text { Number of aa. } \\
\text { rectae }\end{array}$ & $\begin{array}{c}\text { Number of } \\
\text { arteries } 2 \mathrm{~cm} \\
\text { apart from } \\
\text { intestinal wall }\end{array}$ \\
\hline 1 & $40-60$ & 29 & $70.4(67-74)$ & $292.3(286-301)$ & $33.3(31-36)$ \\
2 & $90-110$ & 31 & $109.2(101-117)$ & $299.0(290-307)$ & $35.8(32-38)$ \\
3 & $200-300$ & 26 & $130.0(126-134)$ & $300.0(298-302)$ & $35.5(33-38)$ \\
4 & $301-400$ & 51 & $132.7(117-148)$ & $304.8(286-325)$ & $36.5(29-43)$ \\
5 & $401-$ & 40 & $133.4(122-148)$ & $300.4(280-326)$ & $36.9(32-42)$ \\
\hline
\end{tabular}




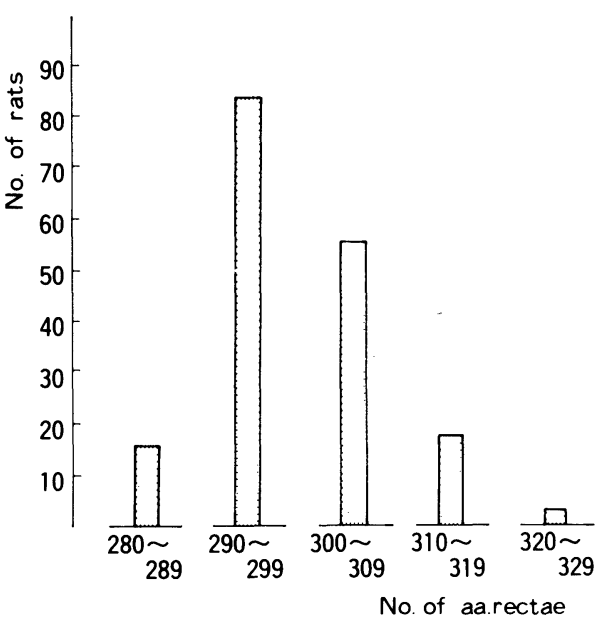

Fig. 2. The numbers of arteriae rectae of the intestinal artery and their distribution (rat).

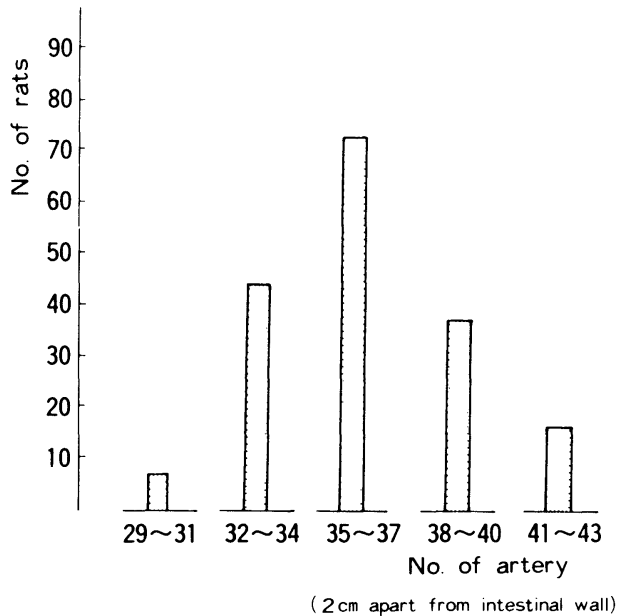

Fig. 3. The numbers of intestinal arteries at the region $2 \mathrm{~cm}$ away from the intestinal wall and their distribution (rat).

TABLE 2. Length of the intestine and the number of aa. rectae of the intestinal artery in human adults

\begin{tabular}{rlccccl}
\hline Case & Sex & $\begin{array}{c}\text { Height } \\
(\mathrm{cm})\end{array}$ & $\begin{array}{c}\text { Weight } \\
(\mathrm{kg})\end{array}$ & $\begin{array}{c}\text { Length of } \\
\text { intestine } \\
(\mathrm{cm})\end{array}$ & $\begin{array}{c}\text { Number of } \\
\text { aa. rectae }\end{array}$ & Diagnosis \\
\hline 1 & Female & 148 & 55 & 532 & 393 & Cholecystolithiasis \\
2 & Female & 148 & 51 & 525 & 428 & Cholecystolithiasis \\
3 & Female & 150 & 51 & 627 & 426 & Cholecystolithiasis \\
4 & Male & 153 & 51 & 610 & 439 & Cholecystolithiasis \\
5 & Female & 154 & 60 & 537 & 434 & Cholecystolithiasis \\
6 & Female & 156 & 56 & 580 & 420 & Cholecystolithiasis \\
7 & Male & 156 & 59 & 686 & 442 & Carcinoma of \\
& & & & & 452 & Challbladder \\
8 & Female & 157 & 71 & 656 & 450 & Duodenal ulcer \\
9 & Male & 164 & 49 & 610 & 450 & Cholecystolithiasis \\
10 & Female & 166 & 56 & 597 & &
\end{tabular}

the number of intestinal arteries in the region about $2 \mathrm{~cm}$ away from the intestinal wall. Their distribution was as shown in Fig. 3, and the mean value on the 177 cases was 36 .

Table 2 shows the results of measurement of the length of intestine and the number of arteriae rectae of human intestinal artery. The length of the small intestine was from 525 to $686 \mathrm{~cm}$ and the mean was $596 \mathrm{~cm}$. The length of the intestinal canal was unrelated to age or body weight but it tended to be longer as the height of the person increased. The length of the intestine was larger for males than females. No conclusion could be drawn, however, since the number 
of subjects employed in this study was too small. The number of arteriae rectae in the intestinal artery was roughly constant, falling within $420-452$, except in one case, and the mean was 433 .

\section{Discussion}

At massive resection of the small intestine, it is necessary to preserve a minimum length of intestinal canal required for digestion and absorption. Recently a hyperalimentation has been commonly used and it has made a significant contribution to the management of patients after enterectomy. In the case of infants, not only maintenance of life but also their later growth must be considered and therefore various surgical techniques have been devised to preserve as much intestine as possible.

In the case of massive resection of the small intestine, it is possible to save life as long as the ileocecal valve and $25-30 \mathrm{~cm}$ of the intestine are preserved (Benson et al. 1967), but when excision of the ileocecal valve is unavoidable, it is necessary to leave at least $45 \mathrm{~cm}$ of intestine (Wilmore 1972). In an extensive aganglionosis, where the colon is also excised, it is said that at least $60 \mathrm{~cm}$ of the small intestine must be preserved (Chiba 1979).

The length of the remaining intestine is usually measured in the morbid condition. However, when an extensive resection is required, the patients have mostly been in ileus-like condition and as a result, the oral side intestine is dilated and extended while the anal side is thin and short due to disuse. When the length of the excised intestine or the length of the intestine to be preserved is determined under such conditions, an error is often produced in comparison with the length measured in the normal condition. It should also be taken into account that as the infant grows, the length of the intestine also increases. There are many reports on the length of the human intestine (Hirsch et al. 1955; Underhill 1955 ; Sotoyama 1958; Reiquam et al. 1961) but the lengths differ according to the method of measurement employed. The measured length is the shortest when a Miller Abbott tube is used in vivo (Hirsch et al. 1955), while the lengths measured at autopsy (Underhill 1955; Sotoyama 1958; Reiquam et al. 1961) tend to be long. The length varies according to the age and height. In the case of a neonate, Benson (1958) reported it was $248 \mathrm{~cm}$ on average and Reiquam and co-workers (1961) reported it was about $300 \mathrm{~cm}$. As body length increases, the intestine length also increases; in the case of adults, it is as long as about 6 m (Underhill 1955; Reiquam et al. 1961). When measured in vivo, it is short, being about $3 \mathrm{~m}$ (Hirsch 1955). In this study, the length measured under general anesthesia was about $6 \mathrm{~m}$, being similar to the value measured by autopsy. In the experiments with rats, no large difference was observed in intestinal length as long as measurement is made under the same conditions.

In order to estimate the normal length of preserved intestine after enterectomy, the number of arteriae rectae of the intestinal artery was measured as an 
index and the number was correlated to the normal length of the intestine. In the case of human, about 20 intestinal arteries branch out from the superior mesenteric artery and they reach the intestinal wall to form many arcades (Licata 1962 ; Anson and McVay 1971). The number of arteriae rectae is somewhat smaller at the end of ileum and at around the duodeno-jejunal junction. The results of this study indicated that this number did not change greatly as they grew from infancy to adultfood. Therefore, when the length of the intestine is measured under general anesthesia and the mean value is calculated, it is possible to obtain the relative length under normal conditions of preserved intestine after massive resection of the intestine, and the length of the intestine in adulthood may also be estimated therefrom.

\section{References}

1) Anson, B.J. \& McVay, C.B. (1971) Abdominal cavity and contents : Jejunum and ileum. In: Surgical Anatomy. 5th ed., W.B. Saunders, Philadelphia, pp. 639-649.

2) Benson, C.D. (1958) Resection and primary anastomosis of jejunum and ileum in the newborn. Ann. Surg. 142, 478-482.

3) Benson, C.D., Lloyd, J.R. \& Krabbenhoff, K.L. (1967) The surgical and metabolic aspects of small bowel resection in the newborn. $J$. pediat. Surg., 2, 227-240.

4) Chiba, T. (1979) Entire colon aganglionosis and extensive aganglionosis in Japan. Jap. J. pediat. Surg., 11, 749-753.

5) Hirsch, J., Ahrens, E.H., Jr. \& Blankenhorn, D.H. (1955) Measurement of the human intestinal length in vivo and some causes of variation. Gastroenterology, 31, 274-284.

6) Licata, R. (1962) Gastrointestinal circulation. In: Blood Vessels and Lymphatics, edited by D.I. Abramson, Academic Press, New York-London, pp. 318-330.

7) Reiquam, C.W., Allen, R.P. \& Akens, D.R. (1961) Normal and abnormal small bowel lengths. Amer. J. Dis. Child., 109, 447-451.

8) Sotoyama, S. (1958) Length of the intestine. In : Nipponjin Jintai Seijo Suchihyo, edited by T. Minoshima, Gihodo, Tokyo, pp. 335-336. (Japanese)

9) Underhill, B.M.L. (1955) Intestinal length in man. Brit. med. J., 19, 1243-1246.

10) Wilmore, D.W. (1972) Factors correlating with successful outcome following extensive intestinal resection in newborn infants. J. Pediat., 80, 88-95. 